\title{
PATTERNS OF PREVENTION OF MALARIA IN PREGNANCY AMONG PREGNANT WOMEN AT SELECTED ANTENATAL CARE FACILITIES, ILISHAN-REMO, OGUN STATE, NIGERIA
}

\section{Ogungbesan Olunike Folake1, Okafor Ngozi Anthonia² and Ogungbesan Joshua Olufemi ${ }^{3}$}

${ }^{1}$ Department of Nursing, Babcock University Teaching Hospital, Ilishan-Remo, Ogun State, Nigeria. Email: ogungbesanolunike@gmail.com

${ }^{2}$ Community/Public Health Nursing, School of Nursing, Babcock University, Ilishan-Remo, Ogun State, Nigeria. Email: okaforn@babcock.edu.ng

${ }^{3}$ Community/Public Health Nursing, School of Nursing, Babcock University, Ilishan-Remo, Ogun State, Nigeria. Email: ogungbesanj@ babcock.edu.ng

Cite this article:

Ogungbesan O.F., Okafor N.A., Ogungbesan J.O. (2021), Patterns OF Prevention OF Malaria in Pregnancy Among Pregnant Women at Selected Antenatal Care Facilities, Ilishan-Remo, Ogun State, Nigeria. African Journal of Health, Nursing and Midwifery 4(2), 105-128. DOI: 10.52589/AJHNMAKIH7UZW.

\section{Manuscript History}

Received: 4 April 2021

Accepted: 18 May 2021

Published: 21 May 2021

Copyright (c) 2020 The Author(s). This is an Open Access article distributed under the terms of Creative Commons AttributionNonCommercial-NoDerivatives 4.0 International (CC BY-NC-ND 4.0 ), which permits anyone to share, use, reproduce and redistribute in any medium, provided the original author and source are credited.
ABSTRACT: Malaria in pregnancy is a preventable infectious disease, yet it remains the cause of maternal, in-utero morbidity and mortality. Pregnant women adopt different patterns of prevention against malaria occurrences and complications. This study aims to identify patterns of malaria prevention among pregnant women inIlishan Remo, Ogun State. In a descriptive cross-sectional study, a purposive sampling technique was used to proportionately select 271 pregnant women attending Ante-natal care (ANC) facilities. A self-administered questionnaire was used to obtained information on 56 items. Data were collected on clinic days for eight weeks duration and analyzed with SPSS 23 (for descriptive frequencies and percentages) and hypotheses tested with chi-square at $p \leq 0.005$. One-third (35.4\%) of the pregnant women aged 31-35years. Predominantly, $80.8 \%$ of the women were Christians, almost half (49.1\%) had tertiary education. The mean of preventive measures used by pregnant women was $27.16 \pm 0.25$. Slightly half (52.4\%) always net windows and doors, $38.4 \%$ always and $53.4 \%$ often cleared bushes around house respectively. About $30.3 \%$ of pregnant women often used IPT-SP and $19.9 \%$ used direct observation therapy (DOT). On the categorized prevention patterns, half (54.2\%) used conventional and $6.64 \%$ non-conventional. There was a significant relationship between the patterns of prevention and ANC facilities $\left(\chi^{2}\right.$ $=20.291)$, beliefs $\left(\chi^{2}=16.540\right)$ at $p<0.005$. The patterns of conventional and non-conventional prevention were used by pregnant women. However, pregnant women should be advised to use the recommended $\mathrm{FMOH/WHO} \mathrm{standard} \mathrm{malaria} \mathrm{prevention} \mathrm{for} \mathrm{safety.}$

KEYWORDS: Pregnant Women, Malaria in Pregnancy, Patterns of Prevention, in-utero and Associated Factors 


\section{INTRODUCTION}

\section{Background to the Study}

Malaria in pregnancy is a preventable infectious disease, yet it remains the major cause of maternal, in-utero, infant morbidity, and mortality. Globally, an estimated 3.4 billion people are at risk of malaria and 1.2 billion at high risk specifically, pregnant women. Predominantly, malaria constitutes a great burden in the sub-Saharan Africa region where about $88 \%$ of malaria cases and $90 \%$ of deaths occurred, of which Nigeria and the Democratic Republic of Congo accounted for more than 35\% (National Multiple Indicator Cluster Survey (NMICS) \& Federal Ministry of Health (FMoH), 2015; WHO, 2018 \& 2019). Annually, about 50 million pregnancies are at risk of malaria infection, and a majority of the pregnant women are in subSaharan Africa, particularly Nigeria. In Nigeria, approximately $70 \%$ of pregnant women suffer from malaria disease and 11\% died (NMICS, 2015 \&Noland et al, 2018).

Malaria is a common notifiable and endemic infectious disease caused by plasmodia (falciparum, vivax, malariae, ovale, and knowles) species. Particularly, pregnant women, inutero and under-five children are most vulnerable to malaria infection and death due to low level of immunity, affinity, and unique taste to pregnant women's blood and hormones (WHO, 2016; Rogerson, Duffy, Leke\& Taylor, 2015). However, in high malaria transmission areas, pregnant women, especially the first-timers, are often susceptible to malaria infection as they are yet to acquire and develop immunity against malaria (Eijk, Hill, Noor, Snow \&Kulie, 2015; Galactionova, Smith, Savigny\& Penny, 2017). Although malaria in pregnancy may not manifest as febrile illness and/or other signs and symptoms, this makes it more dangerous in pregnant women. Malaria could interfere with the maternal-fetal exchange of the placenta thereby causing low birth weight, stillbirths, preterm, failure to thrive in infants(WHO,2016). Whilst in the mother, it causes anemia, abortions, and subsequently other pregnancy-related complications (shock and death) (Bekele, 2016). Despite the several efforts attempted to the prevention of malaria in pregnancy both in the developing and developed world. However, malaria remains a great burden, thus slowing down the targets of sustainable development goals attainment (Rollback Malaria and SDGs, 2018).

The WHO recommended a modifiable approach of a three-prong pattern of malaria prevention and for pregnant women as uptake of Intermittent Preventive Treatment (IPTp-Sp), use of Insecticide Treated Nets (ITNs) (WHO, FMoH\& RBM, 2015). Specifically, targeting pregnant women through maternal and child health services (Rollback Malaria, 2018 \& WHO, 2018). Simultaneously, pregnant women in endemic areas use different patterns of prevention measures such as mosquito repellants coil, herbs, self-medication, sanitation, indoor residual spraying for prevention of malaria in pregnancy (WHO, 2015). For instance, a communitybased study in Ogun State revealed that pregnant women used various items to prevent malaria in pregnancy which includes; insecticide and chemicals spray (70.9\%), clean surroundings (24.2\%), use of window/door screens (16.2\%), ITNs (15.2\%), taking home drugs (2.9\%), using untreated nets $(2.4 \%)$, herbs $(1.0 \%)$, avoiding stress $(0.4 \%)$ and very few $(1.6 \%)$ not taking any preventive step against malaria (Adeneye, Jegede\&Adeniyi, 2016).

Generally, pregnant women seek and use various preventive measures against malaria. Nevertheless, some patterns could be beneficial like the WHO-recommended approach of Intermittent Preventive Treatment (IPTp-Sp), use of Insecticide Treated Nets (ITNs), others (Herbs/herbal concoction, self-medication) could pose risk to pregnancy and its outcomes 
(Alessandro et al., 2018). Invariably, pregnant women are persistently influenced by a number of factors such as; socio-economic, traditional, and religious beliefs, knowledge, family members, attitude, and perception that may inform the patterns of prevention for malaria (Pell et al., 2016). Hence, there is a need to identify patterns of prevention of malaria in pregnancy among pregnant women in Ilishan- Remo, Ogun State.

\section{Statement of the Problem}

Despite the World Health Organization, Ministries of Health and different collaborating bodies' efforts towards the prevention and control of malaria in pregnancy, yet malaria in pregnancy remains an issue. Although, not only in the developing countries, even in all the malaria-endemic regions of the world. Malaria in pregnancy incidence is being indicated to continue to rise as a result of multiple factors; reduced $\mathrm{WHO} / \mathrm{FMOH}$ recommended measures supply, suspected resistance to some drugs, changes in ITN chemicals, behavioral factors to measure utilization against malaria (Alessandro et al., 2018). Invariably, these may have been contributed to pregnant women using alternative preventive patterns such as local herbs, selfmedication, and spiritual measures. A study by Adebayo, Akinyemi\& Cadmus, (2015) revealed that pregnant women in the rural areas believe in myths about the patterns of malaria prevention, using native medicines, and consulting alternative care providers.

According to the World Malaria Report (2019), shown that in 2018 about 19 countries in subSaharan Africa and India accounted for more than $80 \%$ of the global malaria burden. Of which, Nigeria, Madagascar, and the Democratic Republic of Congo had the highest estimated increase, greater than half a million cases (WHO, 2018). In Nigeria, malaria in pregnancy is rated as one of the persistent leading prevailing illnesses affecting pregnant women, and inutero under-five (National Bureau of Statistics (NBS) \&FMoH, 2016). Similarly, as evidence in the Ogun State health Index's 2019 data report, that malaria in pregnancy, particularly the confirmed uncomplicated cases accounted for about $80 \%$. A study in Oyo State also found that about $42 \%$ of pregnant women are often diagnosed with malaria and consequently affecting inutero, infants, and under-five (Ogun State Ministry of Health, 2020 \&Akanbi, 2009). Inadvertently, this resulted in the recent upsurge of cases in the last few years.

Nevertheless, studies have also documented the use of WHO/FMoH recommended patterns of prevention amongst pregnant women particularly in urban areas, but studies are yet to give attention to patterns of prevention of malaria in semi-urban and rural areas. Although, the various patterns of prevention used in pregnancy may directly or inversely affect the cases of malaria in pregnancy. Hence there is need to identify patterns of prevention of malaria used by pregnant women in Ilishan-Remo.

\section{Objective of the Study}

The main objective of this study is to identify patterns of prevention of malaria among pregnant women in Ilishan Remo, Ogun State, Nigeria.

The specific objectives of the study are to;

1. Identify the socio-demographic characteristics of the pregnant women attending selected antenatal care facilities in Ilishan-Remo. 
2. Identify the patterns of malaria prevention among pregnant women attending selected antenatal care facilities.

3. Estimate the total measure of prevention used by pregnant women in the ante-natal care facility

4. Determine the factors associated with patterns of malaria prevention among pregnant women.

\section{Research Questions}

1. What are the socio-demographic characteristics of the pregnant women attending selected antenatal care facilities?

2. What are the patterns of malaria prevention used by pregnant women attending selected antenatal care facilities?

3. What is the total estimate of patterns used by pregnant women

4. What are the factors associated with the patterns of malaria prevention used by pregnant women in the Ilishan-Remo Community?

\section{Hypotheses}

1. There is no significant relationship between socio-demographic characteristics and patterns of malaria prevention used by pregnant women.

\section{Significance of the Study}

As a way of contributing to existing knowledge, findings from this study would reveal the patterns of prevention of malaria use in pregnancy by pregnant women. It may also help to identify the factors associated with patterns of prevention of malaria in pregnancy. Findings from this study might also help to notify various concerned relevant stake-holders on the need to effectively and strategically decide, improve, develop and design an achievable intervention/alternative program to promote adoption and utilization of appropriate recommended preventive patterns for malaria in pregnancy. It may serve as a template for adoption and reference for decision-makers in Ilishan and other similar settings (endemic and high malaria transmission areas) to appropriately plan a way forward to improve the healthy livelihood of pregnant women, in utero and the family at large towards achieving the sustainable development goal of "Zero malaria-free areas" ( SDGs).

\section{Scope of the Study}

The study focused on the patterns of prevention of malaria among pregnant women attending Ante-natal Clinics of Babcock University Teaching Hospital (BUTH), Primary Health Centers, and Community Hospital in Ilishan-Remo. 


\section{Operational definition of terms.}

Malaria in pregnancy: malaria infection occurring in pregnant women.

Patterns of prevention: are measures used by pregnant women to protecting selves against malaria infection such as intermittent preventive treatment (IPTp-Sp), ITN, netting of windows and doors, indoor residual spray, herbs, anointing oil.

Pregnant women: are women attending ante-natal clinic (ANC) in health care facilities in Ilishan-Remo community.

Conventional are ITN, clean surroundings, drainages, IPT, IRS, screening and closing Windows/doors, clearing bushes, protective clothing, mosquitoes repellant, fan and light rooms/house, and avoid stress.

Non-conventional are herbs, mosquito coils, burning substances, Faith home measures, Sel medication, and Sprinkle kerosene.

\section{THEORETICAL FRAME WORK}

\section{Health Belief Model}

The Health Belief Model (HBM) is a social psychological behavior that was developed in the 1950s by social psychologists Irwin, Rosenstock, Godfrey, Hochbaum, Stephen Kegeles, \& Howard Leventhal at the U.S Public health Service in order to understand the failure of people to adopt disease prevention and management strategies or screening tests for the early detection of disease. The HBM suggests that a person's belief in a personal threat of an illness or disease together with a person's belief in the effectiveness of the recommended health behavior or action will predict the likelihood the person will adopt the behavior. Under HBM, there are six constructs, the first four constructs were developed as the original tenets of the HBM. The last two were added as research about the HBM evolved.

Key elements of the Health Belief Model focus on the following variables;

Perceived susceptibility, perceived severity, perceived benefits, perceived barriers, cue to action, and self-efficacy 


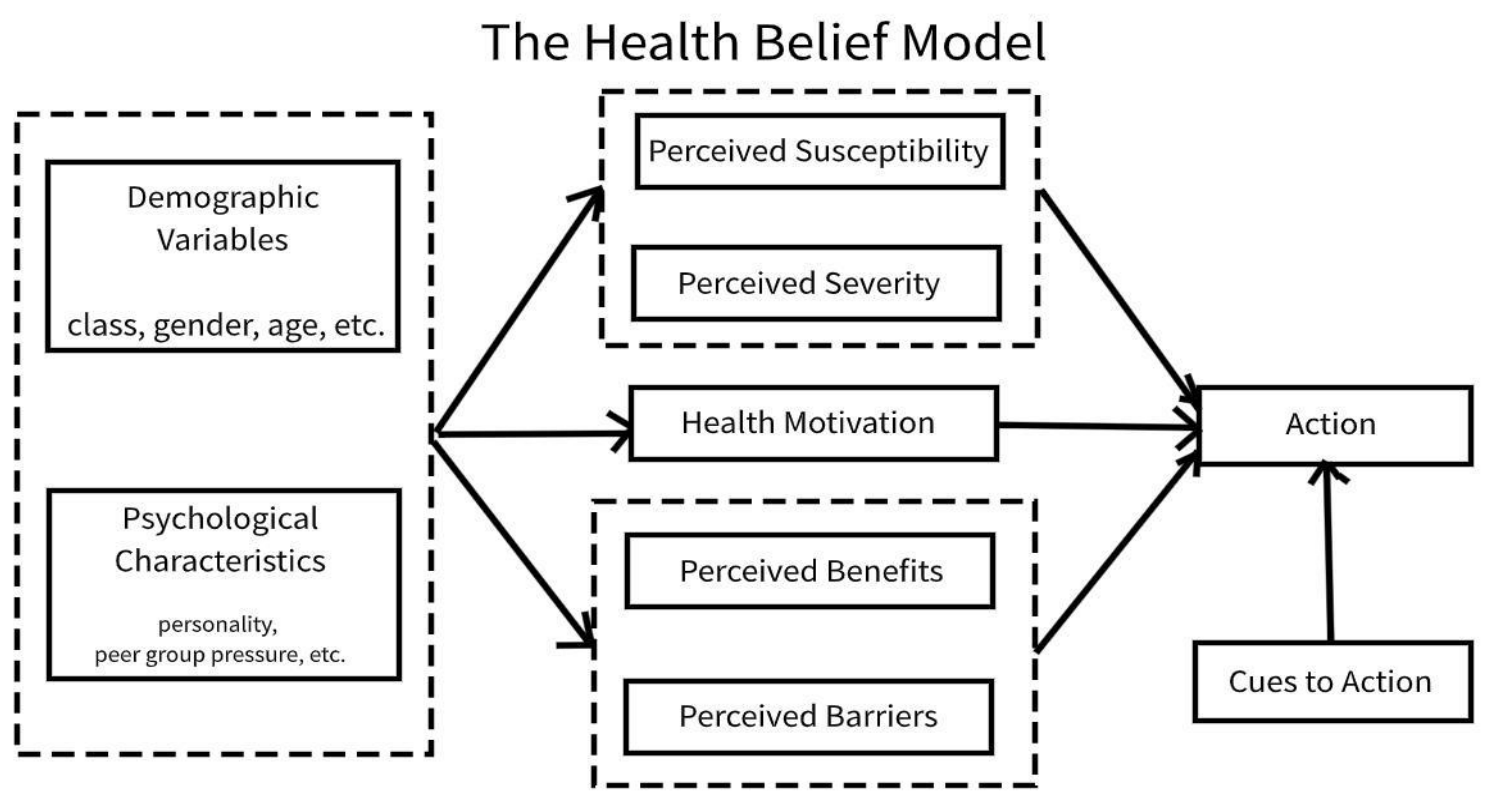

Figure 2.1: Health Belief Model

Source: Irwin, Rosenstock, Godfrey, Hochbaum, Stephen Kegeles, \& Howard Leventhal, (1950)

\section{Application of Health Belief model to patterns of prevention of malaria in pregnancy}

The conceptual framework applied to this study is the Health belief model, which is based on individual perception about a disease condition, severity/seriousness which enables individual to take certain actions to prevent the severity of the disease condition when the benefits or effectiveness of various actions available to reduce the threat of illness or disease are being perceived.

Socio-Demographic Variables: Socio-demographic variables are age, occupation, level of education attainment, ethnicity, and religion, socio-economic which are associated with the patterns of malaria prevention sought after and used by pregnant women during pregnancy.

Perceived Susceptibility: Pregnant women in this study perceived to be at risk of contracting malaria infection as a result of low level of immunity.

Perceived Severity: Pregnant women in this study believed that malaria in pregnancy could cause complications such as; anemia, stillbirth, intrauterine growth restriction, preterm contraction etc.

Perceived Benefits: Pregnant women believed that adopting preventive measures could prevent malaria infection during pregnancy. The benefits of taking action are an individual decision and believed which based on previous positive experience and pregnancy outcome .Furthermore, this determines the kind of ANC facility to use and patterns of prevention to adopt in the pregnancy such as (ITN, IPT-sp, IRS ) or/and others non-conventional patterns of 
prevention such as (Herbs/herbal concortion, products from faith based antenatal care facilities such as; anointing oil, holy water and prayers, while some patronize patent medicine stores.

Cues to action: These are the information gotten at ANC, media, motivation from friends, family members on how to take preventive actions.

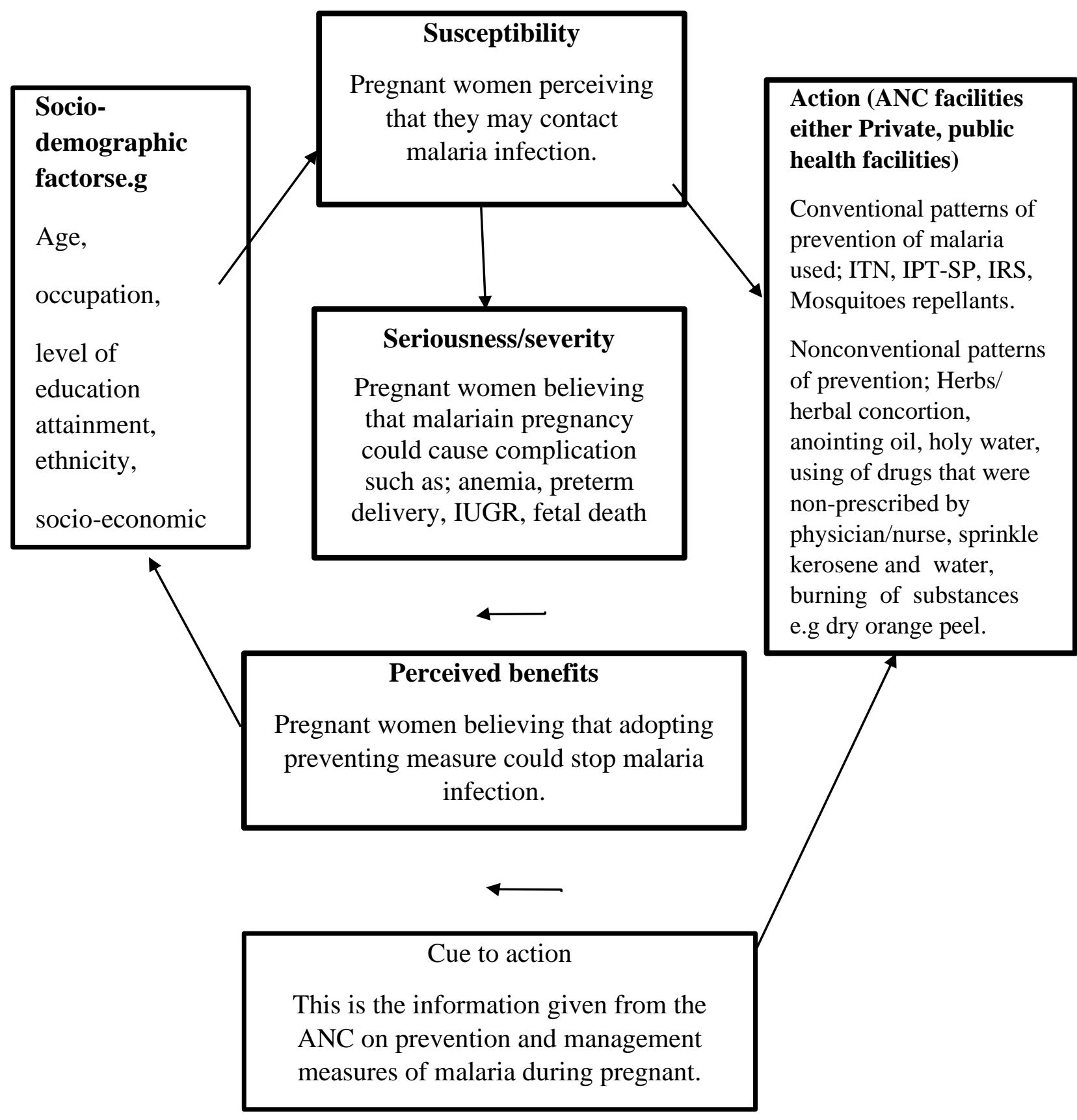

Figure 2.2 Adapted model from Health Belief Model 


\section{RESEARCH METHODOLOGY}

\section{Research Design}

A descriptive cross-sectional study utilizing quantitative (survey) design to identify patterns of prevention of malaria among pregnant women attending Antenatal clinic in Ilishan- Remo, Ikenne Local Government Area, Ogun State.

\section{Research setting}

This study was carried out in Ilishan-Remo community, Ikenne Local Government Area, Ogun State. The fourth-largest community in Remo-land and amongst the five communities (Akarigbo, Elepe, Alalisan, Alara\&Alado) that migrated from Iremo quarters in Ile-Ife between 1400 and 1438 A.D (Ojomah, 2015). One of the 33 towns that made up the ethnic group called Remo community in Yoruba land and popularly called Remo metalelogbon (Nwaomah, Audu\& Dickson, 2010).Ilishan-Remo appears to be the most centrally located community in the heart of Remo Land and situated within Irepodun district in Ikenne Local Government Area. It was one of the towns that made up Ikenne Local Government Area and culturally, practices Egungun festival, Isanbi, Isemo/ Oro as well rich with Christianity and Islam (Badmus\&Adamo, 2007).

It comprises the rural and sub-urban areas popularly called town and town planning areas respectively. It has two political wards with a total population of 10,309 (National Population Commission (NPC), 2006). The community was into trading of mainly Kola nuts and businesses, civil/public services, industrial activities, farming and vocational works like the weaving of baskets, calabash making, plaiting of hair, wood carving, and native doctors (herbalists) that give identity, security, and livelihood to the populace (Adamo, 2007).

The community has facilities like healthcare facilities, schools, and so on. The antenatal facility comprises a tertiary health institution, the Primary Healthcare Centres (PHC), Mission houses, and traditional birth attendants (Abiye) distributed at different locations within the study area.

\section{Population}

The study targeted the booked pregnant women attending antenatal clinics in the selected facilities in Ilishan-Remo Community, Ogun state.

\section{Inclusion Criteria}

1. Pregnant women attending ANC facilities in Ilishan-Remo community.

2. Pregnant women willing to participate in the study at selected health facilities in IlishanRemo, Ogun State

\section{Exclusion criteria}

1. Pregnant women who were not booked and visiting ANC facilities for the first time for health service in Ilishan-Remo

2. Pregnant women not willing to participate in the study. 
African Journal of Health, Nursing and Midwifery

ISSN: 2689-9418

Volume 4, Issue 2, 2021 (pp. 105-128)

www.abjournals.org

\section{Sample size Determination}

Using the sample size formula for cross sectional studies:

$\mathrm{n}=\mathrm{Z}^{2} \rho \mathrm{q} / \mathrm{d}^{2}($ Leshie Kish Formula)

Where $Z=1.96$, (Level of significance of $5 \%$ (1.96))

$\mathrm{p}=82 \%$, (as the proportion of pregnant women utilizing prevention and management of malaria in a rural community of Ogun state, Nigeria by Adeneye et al., 2014)

$\mathrm{q}=1-\mathrm{p}=18 \%$

$\mathrm{d}=5 \%$ (precision accuracy)

$\mathrm{n}=$ Sample size

$\mathrm{n}=1.96^{2} \times 0.8 \times 0.20 .05^{2}$

$\mathrm{n}=3.84 \times 0.8 \times 0.2 / 0.0025$

$\mathrm{n}=245.76$

$\mathrm{n}=246$

The study sample size was 246 with a non-response rate of $10 \%$ added at approximately 25

Therefore, the total estimate number of expected respondents for the study is $n=271$

\section{Sample size and Sampling Technique}

1. The study was carried out in four selected antenatal care facilities in Ilishan-Remo.

2. Average pregnant women attendees per month in the selected ANC facilities were 440

3. Based on the attendance per month 440 , the sample size of 271 pregnant women was proportionately selected for the study.

4. The pregnant women were selected using convenient sampling method.

Table 2: Proportionate sample at Selected ANC facilities

\begin{tabular}{|l|l|l|l|}
\hline \multicolumn{1}{|c|}{ ANC facilities } & $\begin{array}{c}\text { Average pregnant women } \\
\text { attendees per month in the ANC } \\
\text { facilities in Ilishan-Remo } \\
\text { Community, } \\
\text { Ogun State }\end{array}$ & \multicolumn{1}{|c|}{$\begin{array}{c}\text { Calculations of } \\
\text { sample size }\end{array}$} & $\begin{array}{l}\text { The proportion of } \\
\text { selection of } \\
\text { respondents in } \\
\text { ANC facilities. }\end{array}$ \\
\hline $\begin{array}{l}\text { Babcock University } \\
\text { Teaching Hospital (BUTH) }\end{array}$ & $200 \quad 200 \times 271 / 440=124$ & 124 \\
\hline PHC 1 (Town Hall) & 80 & $80 \times 271 / 440=49$ & 49 \\
\hline Community Hospital & 100 & $100 \times 271 / 440=61$ & 61 \\
\hline $\begin{array}{l}\text { PHC 2 (Old police station } \\
\text { Ago-Ilara) }\end{array}$ & 60 & $60 \times 271 / 440=37$ & 37 \\
\hline TOTAL & $\mathbf{4 4 0}$ & & $\mathbf{2 7 1}$ \\
\hline
\end{tabular}




\section{Instrumentation}

The study utilized a self-developed questionnaire to collect data on the patterns of prevention of malaria in pregnancy. The questions were drawn from the specific objectives of the study and 33-question items were formed and into three sections as (A-C). Thus comprised of;

Section A: comprised of six close-ended questions that assessed the socio-demographic characteristics of pregnant women which include age, occupation, level of educational attainment, ethnicity, religion, average monthly income.

Section B: comprised of 19 close-ended questions on a rating scale of (1-3) that identified the patterns of malaria prevention among pregnant women with always, often and never.

Section C: consisted of eight closed-ended questions on factors associated with patterns of prevention of malaria in pregnancy with true and false.

The instrument was translated to Yoruba language for easy comprehension and related to the language at convenience.

\section{Reliability and Validity of the Instrument}

\section{Validity of the Instrument}

The validity of the instrument was determined by subjecting the instrument to face and content validity, which involved scrutiny of the instruments to ensure it measures the extent to which the instrument related to the patterns of prevention of malaria in pregnancy. Also, experts in the field of Research and Statistics reviewed the instrument.

\section{Reliability of the Instrument}

The instrument was pre-tested on 27 pregnant women in Primary Health Care Center in Iperu -Remo community, Ogun state on patterns of prevention of malaria in pregnancy, and the responses were analyzed using Cronbach's alpha coefficient for the reliability and score of $0.82,0.78$ and 0.73 respectively considered as consistent and suitable.

\section{Method of Data Collection}

A self-administered method was used to collect data from study participants after approval was gotten from the BUHREC ethical committee and letter of permission from the Human Resources of Babcock University Teaching Hospital (BUTH) and the Chief Medical Director in-charge of Primary Healthcare Centers in Ikenne Local Government. The approvals were taken to the heads of ANC facilities where data collection took place and the purpose of the study was discussed with each ANC Managers. The researchers explained the purpose of the research to the participants and also charged by the heads of the facilities and research assistants to gain their full participation. Pregnant women that were willing, accepted an informed consent form to sign before recruiting them for the study. The researcher guaranteed the confidentiality of the participants as their respective names and addresses were not required.

The duration of the data collection on the field took eight weeks, and with the aid of three trained research assistants on the clinic days only. 


\section{Method of Data Analysis}

The study data were sorted, coded, and entered into the spreadsheet and analyzed using SPSS version 23.0 statistical software (SPSS Inc. USA). The anti-malaria measures used were categorized into patterns of prevention as conventional (ITN, cleaning surroundings, drainages, IPT, IRS, screening, and closing Windows/doors, clearing bushes, protective clothing, mosquitoes repellant, fan, and light rooms/house, and avoid stress), non-conventional (herbs, mosquitoes coils, burning substances, faith home measures, buying patent drugs and sprinkle kerosene) and combination of conventional and non-conventional patterns based on their responses and recorded as one to three and organized identified patterns in a logic, concise and charity manner for computation, analysis, and presentation in summary. The variables were analyzed descriptively; percentage and frequency, mean and bivariate; using the chi-square test to hypotheses ATP-value $<0.05$.

\section{Ethical Consideration}

Ethical approval was obtained from Babcock University Health Research Ethics Committee (BUHREC). The letter of introduction was given to the Human Resources of Babcock University Teaching Hospital, the Medical Officer in charge of Health at the Primary Healthcare Centers in Ikenne Local Government, and the ante-natal care facilities managers. Also, the participants were fully informed about the nature of the study that their participation was voluntary. The researcher ensured anonymity, beneficences and non-maleficence, and respect.

\section{DATA ANALYSIS, RESULTS, AND DISCUSSION OF FINDINGS}

A total of 271 questionnaires were administered to the respondents, all were filled and returned with the help of research assistants and constituted a response rate of $100 \%$.

\section{Socio-demographic characteristics of Study participants}

Table 3: Socio-demographic characteristics of pregnant women attending ante-natal facilities

\begin{tabular}{|l|l|l|l|}
\hline S/N & Socio-demographic & Frequency (n-271) & Percentage (\%) \\
\hline 1. & Age & & \\
\hline & $\leq 25$ years & 43 & $15.9 \%$ \\
\hline & 26- 30 years & 78 & $28.8 \%$ \\
\hline & 31- 35 years & 96 & $35.4 \%$ \\
\hline & $36-40$ years & 37 & $13.7 \%$ \\
\hline & 41years and above & 17 & $6.3 \%$ \\
\hline 2. & Occupation & & \\
\hline & Salary Earners & 66 & $24.4 \%$ \\
\hline & Trader & 104 & $38.4 \%$ \\
\hline & Artisan & 59 & $21.8 \%$ \\
\hline & Apprentice & 17 & $6.3 \%$ \\
\hline & House wife & 25 & $9.2 \%$ \\
& & & \\
\hline
\end{tabular}


African Journal of Health, Nursing and Midwifery

ISSN: 2689-9418

Volume 4, Issue 2, 2021 (pp. 105-128)

www.abjournals.org

\begin{tabular}{|l|l|l|l|}
\hline 3. & Educational level & & \\
\hline & No formal education & 15 & $5.5 \%$ \\
\hline & Primary & 27 & $10.0 \%$ \\
\hline & Secondary & 96 & $35.4 \%$ \\
\hline & Tertiary & 133 & $49.1 \%$ \\
\hline 4. & Ethnicity & & \\
\hline & Yoruba & 175 & $64.6 \%$ \\
\hline & Igbo & 60 & $22.1 \%$ \\
\hline & Hausa & 18 & $6.6 \%$ \\
\hline & Others & 18 & $6.6 \%$ \\
\hline 5. & Religion & & \\
\hline & Christianity & 219 & $80.8 \%$ \\
\hline & Islam & 51 & $18.8 \%$ \\
\hline & Traditional & 1 & $0.4 \%$ \\
\hline 6. & Income level(Monthly) & & \\
\hline & $\# \leq 20000$ & 68 & $25.1 \%$ \\
\hline & $\# 21000-30000$ & 51 & $18.8 \%$ \\
\hline & $\# 31000-40000$ & 39 & $14.4 \%$ \\
\hline & $\# 41000-50000$ & 34 & $12.5 \%$ \\
\hline & $\# 51000$ and above & 79 & $29.2 \%$ \\
\hline
\end{tabular}

The above table 3 displays the socio-demographic characteristics of the pregnant women. Onethird $(35.4 \%)$ of the respondents were between the ages 31-35years. Nearly two-fifth $(38.4 \%)$ of the pregnant women were traders, almost half $(49.1 \%)$ had tertiary education. Furthermore, majority $(80.8 \%)$ were Christians and, two-thirds $(64.6 \%)$ of the pregnant women were Yoruba, and other tribes (Egun, Irobo) were only 6.6\%. The monthly income of the pregnant women showed that the above quarter (29.2\%) earned 51000 naira and above (see table 4.1).

Table 4: Patterns of Malaria Preventive Measures used by Pregnant Women

\begin{tabular}{|c|c|c|c|c|}
\hline \multirow[t]{2}{*}{$\mathbf{S} / \mathbf{N}$} & \multirow[t]{2}{*}{ Malaria Preventive items } & \multicolumn{3}{|c|}{ Frequency $(n-271) \quad$ Percentage $(\%)$} \\
\hline & & Always n (\%) & Often n (\%) & Never n (\%) \\
\hline 7 & Sleeping under ITN & $78(28.8 \%)$ & $36(13.3 \%)$ & $157(57.9 \%)$ \\
\hline 8 & Using Mosquitoes coil & $11(4.1 \%)$ & $42(15.5 \%)$ & $218(80.4 \%)$ \\
\hline 9 & $\begin{array}{l}\text { Using herbs (Pawpaw,dogoyaro } \\
\text { and mango bark) }\end{array}$ & $0(0.0 \%)$ & $44(16.2 \%)$ & $227(83.8 \%)$ \\
\hline 10 & Using Aloe vera plants & $0(0.0 \%)$ & $13(4.8 \%)$ & $258(95.2 \%)$ \\
\hline 11 & $\begin{array}{l}\text { Using Indoor Residual Spray(e.g } \\
\text { raid) }\end{array}$ & $54(19.9 \%)$ & $47(17.3 \%)$ & $170(62.7 \%)$ \\
\hline 12 & $\begin{array}{l}\text { Draining and cleaning water } \\
\text { channels/gutter }\end{array}$ & $76(28.0 \%)$ & $53(19.6 \%)$ & $142(52.4 \%)$ \\
\hline 13 & Wearing protective clothes & $30(11.1 \%)$ & $45(16.6 \%)$ & $196(72.3 \%)$ \\
\hline 14 & $\begin{array}{l}\text { Burning substance (dry orange } \\
\text { peel) }\end{array}$ & $2(0.7 \%)$ & $7(2.6 \%)$ & $262(96.7 \%)$ \\
\hline
\end{tabular}




\begin{tabular}{|l|l|l|l|l|}
\hline 15 & $\begin{array}{l}\text { Using Faith home measures (e.g } \\
\text { oil, soap) }\end{array}$ & $28(10.3 \%)$ & $45(16.6 \%)$ & $198(73.1 \%)$ \\
\hline 16 & Tidy-up surroundings & $98(36.2 \%)$ & $90(33.2 \%)$ & $83(30.6 \%)$ \\
\hline 17 & $\begin{array}{l}\text { Cuttingof bushes around the } \\
\text { house }\end{array}$ & $104(38.4 \%)$ & $146(53.9 \%)$ & $21(7.7 \%)$ \\
\hline 18 & Closing windows and doors & $71(26.2 \%)$ & $119(43.9 \%)$ & $81(29.9 \%)$ \\
\hline 19 & Sprinkle of kerosene and water & $3(1.1 \%)$ & $11(4.1 \%)$ & $257(94.8 \%)$ \\
\hline 20 & Netting of windows and doors & $142(52.4 \%)$ & $42(15.5 \%)$ & $87(32.1 \%)$ \\
\hline 21 & Using fan and lighting the room & $17(6.3 \%)$ & $50(18.5 \%)$ & $204(75.3 \%)$ \\
\hline 22 & $\begin{array}{l}\text { Buying and using drugs from } \\
\text { patent medicine store }\end{array}$ & $23(8.5 \%)$ & $82(30.3 \%)$ & $166(61.3 \%)$ \\
\hline 23 & Using IPT- SP Fansidar & $52(19.2 \%)$ & $82(30.3 \%)$ & $137(50.5 \%)$ \\
\hline 24 & $\begin{array}{l}\text { Taking IPT-SP Fansidar under } \\
\text { DOT Using mosquitorepellant } \\
\text { (e.godomos) }\end{array}$ & $\begin{array}{l}47(17.4 \%) \\
19(7.0)\end{array}$ & $\begin{array}{l}54(19.9 \%) \\
23(8.5 \%)\end{array}$ & $170(62.7 \%)$ \\
$229(84.5 \%)$
\end{tabular}

Mean measures of prevention used 27.16 \pm 0.25

Table 4.shows the distribution rate and total sum of the various malaria preventive measures used by pregnant women. The mean of total preventive measures used was $27.16 \pm 0.25$. Nearly one-third $(28.8 \%)$ of the pregnant women always slept under an insecticide net. One-third $(36.2 \%)$ and $(33.2 \%)$ of the pregnant women always and often cleaned their surroundings respectively. About an average (52.4\%) number of pregnant women always net their windows and doors while $43.9 \%$ often close windows and doors. About (38.4\%) of the pregnant women always and 53.9\% often clear bushes around the house respectively. One-third (30.3\%) often used IPT-SP and majority (62.7\%) never took IPT-SP under direct observational therapy.

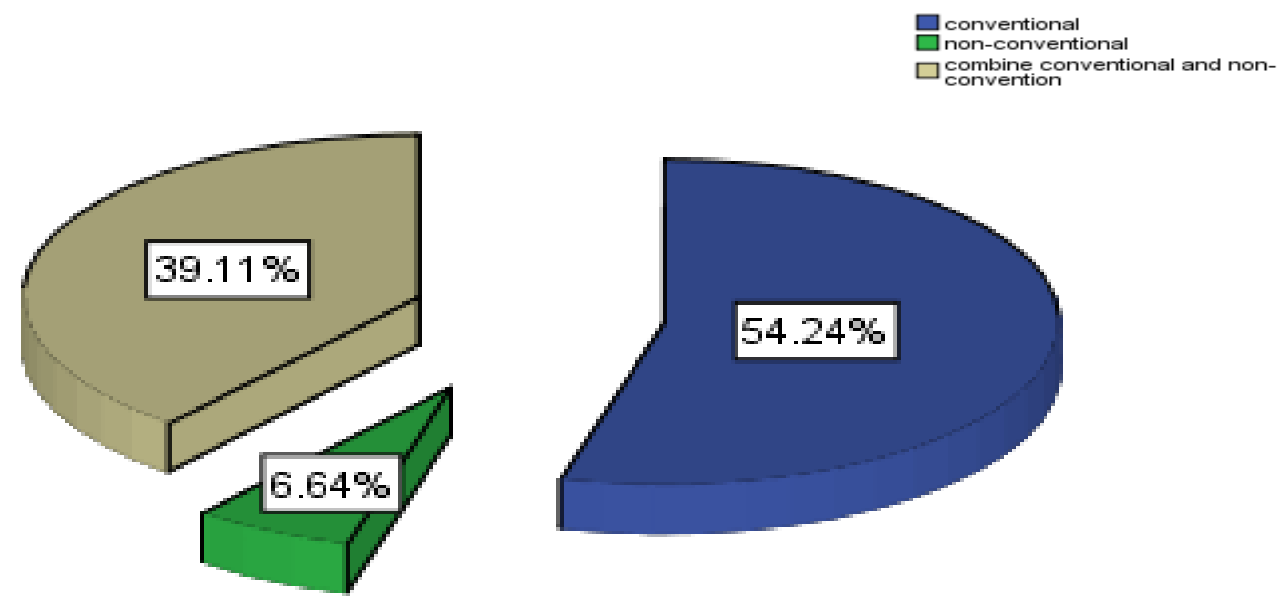

Figure 1: Categorized patterns of malaria preventive measures used by pregnant women 
Figure 1 above shows a pie chart proportion of categorized preventive measures as conventional, non-conventional, and a combination of both the conventional and nonconventional patterns. Slightly more than half $(54.24 \%)$ of the pregnant women used conventional pattern only, $39.11 \%$ used both conventional and non-conventional, and very few $(6.64 \%)$ used non-conventional pattern only for malaria prevention.

*Conventional as ITN, cleaning surroundings, drainages, IPT, IRS, screening and closing Windows/ doors, clearing bushes, protective clothing, mosquitoes repellant, fan, and light rooms/house, and avoid stress.

**Non-conventional as herbs, mosquitoes coils, burning substances, Faith home measures, buying patent drugs, and Sprinkle kerosene ***Combination of conventional and nonconventional patterns.

Table 6: Factors Associated with Patterns of Malaria Prevention among Pregnant Women at ANC

\begin{tabular}{|c|c|c|c|}
\hline $\mathbf{S} / \mathbf{N}$ & Factors & Frequency (n -271) & Percentage (\%) \\
\hline \multirow[t]{3}{*}{26} & Information from ANC attendant & & \\
\hline & True & 239 & $88.2 \%$ \\
\hline & False & 32 & $11.8 \%$ \\
\hline \multirow[t]{3}{*}{27} & Knowledge of Malaria prevention & & \\
\hline & True & 191 & $70.5 \%$ \\
\hline & False & 80 & $29.5 \%$ \\
\hline \multirow[t]{3}{*}{28} & Previous experiences with malaria & & \\
\hline & True & 157 & $57.9 \%$ \\
\hline & False & 114 & $42.1 \%$ \\
\hline \multirow[t]{3}{*}{29} & Family recommendation & & \\
\hline & True & 171 & $63.1 \%$ \\
\hline & False & 100 & $36.9 \%$ \\
\hline \multirow[t]{3}{*}{30} & Cost of ANC care & & \\
\hline & True & 259 & $95.6 \%$ \\
\hline & False & 12 & $4.4 \%$ \\
\hline \multirow[t]{3}{*}{31} & Quality of ANC care services & & \\
\hline & True & 262 & $96.7 \%$ \\
\hline & False & 9 & $3.3 \%$ \\
\hline \multirow[t]{3}{*}{32} & Positive attitude of ANC attendant & & \\
\hline & True & 233 & $86.0 \%$ \\
\hline & False & 38 & $14.0 \%$ \\
\hline \multirow[t]{3}{*}{33} & Beliefs in Traditional care & & \\
\hline & True & 134 & $49.4 \%$ \\
\hline & False & 137 & $50.6 \%$ \\
\hline
\end{tabular}


Table 6 displays the distribution of factors associated with malaria preventive measures used by pregnant women. Majority of the factors including; quality and cost of ANC services, information from ANC attendants, positive attitude were claimed associated with patterns of malaria prevention used by pregnant women as $96.7 \%, 95.6 \%, 88 \%$ and $86 \%$ respectively. Also, almost half $(49.4 \%)$ and $(42.1 \%)$ claimed that beliefs in traditional care and previous experience with malaria outcome were factors relating to malaria prevention (see table 4).

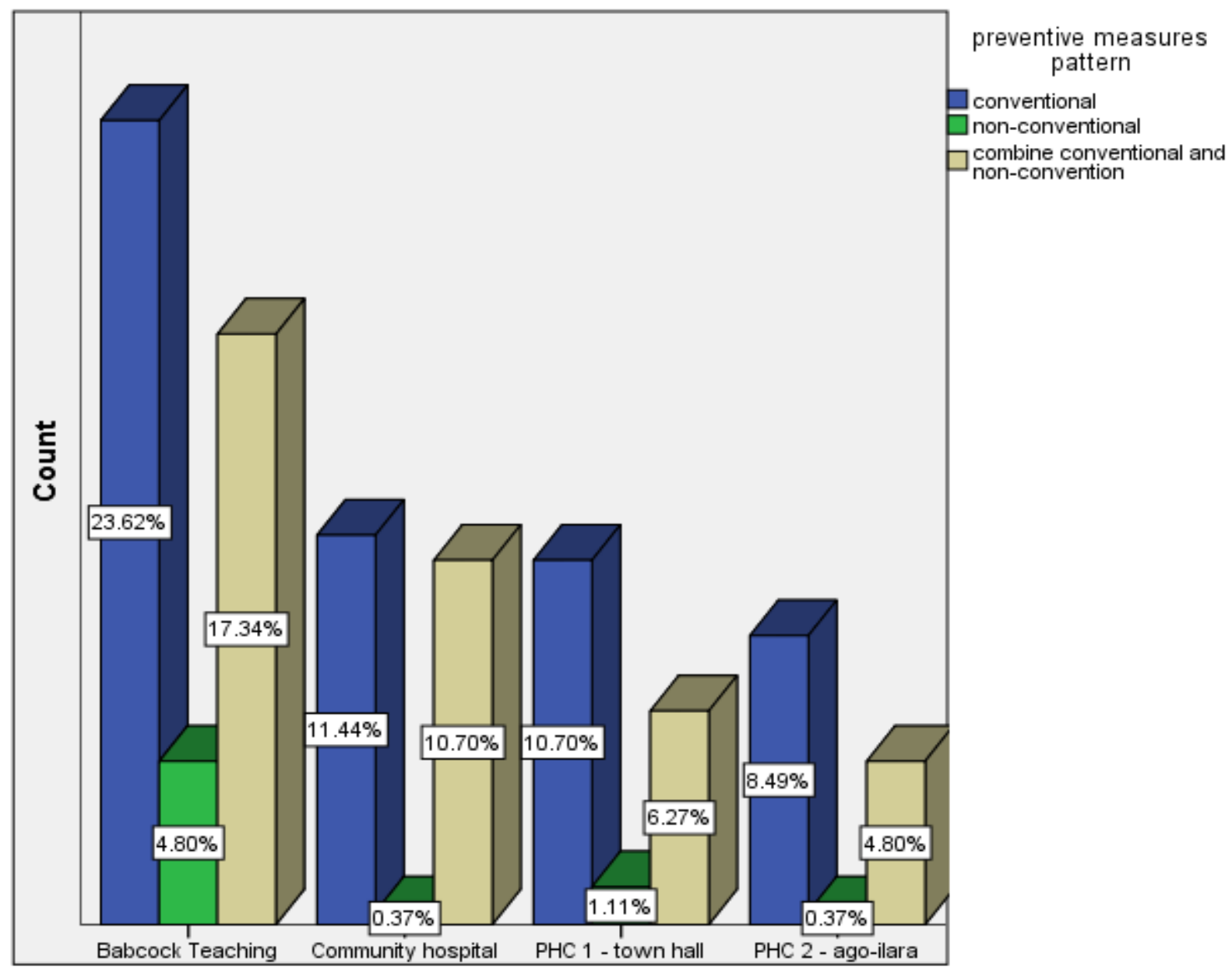

Figure 2: Pattern of malaria prevention used by pregnant women according to healthcare facilities for ANC

The above-clustered bar chart displays the proportion of categorized patterns of malaria prevention used by pregnant women across various health facilities attended for ante-natal care services. Majority $(23.62 \%)$ of the pregnant women at the BUTH used conventional pattern followed by those in Ilishan community $11.44 \%$, PHC-I $10.70 \%$, and PHC-II $8.46 \%$ respectively. 


\section{Hypothesis one}

Table 8: The relationship between the Socio-demographic Characteristics and Patterns of malaria Prevention in Pregnancy

\begin{tabular}{|c|c|c|c|c|c|c|}
\hline $\begin{array}{l}\mathbf{S} / \\
\mathbf{N}\end{array}$ & $\begin{array}{c}\text { Socio- } \\
\text { demographic } \\
\text { variables }\end{array}$ & $\begin{array}{c}\begin{array}{c}\text { Convention } \\
\text { al }\end{array} \\
\text { n }(\%)\end{array}$ & $\begin{array}{c}\text { Non- } \\
\text { conventional } \\
\text { n }(\%)\end{array}$ & $\begin{array}{c}\text { Combination of } \\
\text { conventional } \\
\text { and non- } \\
\text { conventional } \\
\text { n }(\%)\end{array}$ & $\begin{array}{c}\text { P- } \\
\text { Value }\end{array}$ & $\chi^{2}$ \\
\hline & ANC facilities & & & & $0.002 *$ & 20.291 \\
\hline & BUTH & $60(48.4 \%)$ & $11(8.9 \%)$ & $53(42.7 \%)$ & & \\
\hline & $\begin{array}{l}\text { Community } \\
\text { Hospital }\end{array}$ & $25(41.0 \%)$ & $1(1.6 \%)$ & $35(57.4 \%)$ & & \\
\hline & PHC 1 & $29(59.2 \%)$ & $3(6.1 \%)$ & $17(34.7 \%)$ & & \\
\hline & PHC 2 & $29(78.4 \%)$ & $1(2.7 \%)$ & $7(18.9 \%)$ & & \\
\hline & Age & & & & 0.592 & 6.491 \\
\hline & $\leq 25$ years & $27(62.8 \%)$ & $3(7.0 \%)$ & $13(30.2 \%)$ & & \\
\hline & 26- 30 years & $40(51.3 \%)$ & $5(6.4 \%)$ & $33(42.3 \%)$ & & \\
\hline & $31-35$ years & $47(49.0 \%)$ & $4(4.1 \%)$ & $45(46.9 \%)$ & & \\
\hline & $36-40$ years & $19(51.4 \%)$ & $4(10.8 \%)$ & $14(37.8 \%)$ & & \\
\hline & $\geq 41$ years & $10(58.8 \%)$ & $0(0.0 \%)$ & $7(41.2 \%)$ & & \\
\hline & Occupation & & & & 0.117 & 12.846 \\
\hline & Salary Earner & $27(40.9 \%)$ & $4(6.1 \%)$ & $35(53.0 \%)$ & & \\
\hline & Trader & $59(56.7 \%)$ & $5(4.8 \%)$ & $40(38.5 \%)$ & & \\
\hline & Artisan & $30(50.8 \%)$ & $7(11.9 \%)$ & $22(37.3 \%)$ & & \\
\hline & Apprentice & $12(70.6 \%)$ & $0(0.0 \%)$ & $5(23.5 \%)$ & & \\
\hline & House wife & $15(60.0 \%)$ & $0(0.0 \%)$ & $10(40.0 \%)$ & & \\
\hline & Educational level & & & & 0.659 & 4.132 \\
\hline & $\begin{array}{l}\text { No formal } \\
\text { education }\end{array}$ & $11(73.3 \%)$ & $0(0.0 \%)$ & $4(26.7 \%)$ & & \\
\hline & Primary & $14(51.9 \%)$ & $2(7.4 \%)$ & $11(40.7 \%)$ & & \\
\hline & Secondary & $53(55.2 \%)$ & $6(6.2 \%)$ & $37(38.5 \%)$ & & \\
\hline & Tertiary & $65(48.9 \%)$ & $8(6.0 \%)$ & $60(45.1 \%)$ & & \\
\hline & Ethnicity & & & & 0.344 & 6.755 \\
\hline & Yoruba & $94(52.5 \%)$ & $12(6.7 \%)$ & $73(40.8 \%)$ & & \\
\hline & Igbo & $32(47.8 \%)$ & $2(3.0 \%)$ & $33(49.3 \%)$ & & \\
\hline & Hausa & $14(70.0 \%)$ & $2(10.0 \%)$ & $4(20.0 \%)$ & & \\
\hline & Others & $3(60.0 \%)$ & $0(0.0 \%)$ & $2(40.0 \%)$ & & \\
\hline & Religion & & & & $0.002 *$ & 16.540 \\
\hline & Christianity & $\begin{array}{l}114 \\
(52.1 \%)\end{array}$ & $13(5.9 \%)$ & $92(42.0 \%)$ & & \\
\hline & Islam & $29(56.9 \%)$ & $2(3.9 \%)$ & $20(39.2 \%)$ & & \\
\hline & Traditional & $0(0.0)$ & $1(100.0 \%)$ & $0(0.0 \%)$ & & \\
\hline
\end{tabular}




\begin{tabular}{|l|l|l|l|l|l|l|}
\hline & Income per Month & & & & 0.921 & 3.201 \\
\hline & $\leq \# 20000$ & $38(55.9 \%)$ & $5(7.4 \%)$ & $25(36.8 \%)$ & & \\
\hline$\# 21000-30000$ & $28(54.9 \%)$ & $1(2.0 \%)$ & $22(43.1 \%)$ & & \\
\hline$\# 31000-40000$ & $20(51.3 \%)$ & $3(7.7 \%)$ & $16(41.0 \%)$ & & \\
\hline$\# 41000-50000$ & $19(55.9 \%)$ & $2(5.9 \%)$ & $13(38.2 \%)$ & & \\
\hline$\geq \# 51000$ & $38(48.1 \%)$ & $5(6.3 \%)$ & $36(45.6 \%)$ & & \\
\hline
\end{tabular}

Conventional as ITN, cleaning surroundings, drainages, IPT, IRS, screening and closing Windows/doors, clearing bushes, protective clothing, mosquitoes repellant, fan, and light rooms/house, and avoid stress, $\square \square$ Non-conventional herbs, mosquitoes coils, Burning substances, Faith home measures, buying patent drugs and Sprinkle kerosene, Combination of conventional and non-conventional patterns.

The above table 4.6 displays the relationship between socio-demographic variable and patterns of categorized malaria prevention used by pregnant women. Few of the socio-demographic variables were related to patterns of malaria prevention, there was a significant relationship between the ante-natal facilities attended and patterns of malaria prevention used. In which, majority of the pregnant women attending an ante-natal clinic at Babcock University Teaching Hospital (48.4\%), Primary health care I (59.2\%) and II (78.2\%) used conventional pattern of prevention to non-conventional and combined conventional and non-convention patterns $\left(\chi^{2}=20.291, \mathrm{p}=0.002\right)$. Also, there was a significant relationship between the religion and patterns of malaria prevention used, in which the majority of the pregnant women who either practiced Christianity and/or Islam used a conventional pattern of malaria prevention $\left(\chi^{2}=16.540, p=0.002\right)$. However, other socio-demographic variables; age, education, socioeconomic status, and occupation were not significantly related to patterns of malaria prevention.

\section{DISCUSSION OF FINDINGS}

This study sought to identify the patterns of prevention of malaria in pregnancy among pregnant women at selected antenatal care facilities, Ilishan-Remo, Ogun State.

\section{Socio-demographic Characteristics}

The age distribution of pregnant women in this present study were grouped, in which majority were aged 31-35 years and 26-30 years commensurate with the findings of Efunshile et al., (2011) and conform to the normal expected female adulthood reproduction period by UNFPA, (2019), WHO, (2015) and to any country demography of reproductive age women distribution (KDHS, 2015\& NDHS, 2018). The women engaged in different activities for a living, particularly in trading, civil services, and artisans as contrary to Sabin et al., (2018), Exavery et al., (2014) and Efunshile et al, (2011) findings as this may own to development characterized by the study setting and its proximity to developed areas. And the findings also reflected what the women were originally known for as prime traders and industrious people (Adamo, 2007).

The pregnant women had more than primary education in this study and corresponds to the findings of Adebayo, Akinyemi, and Cadmus (2015) that reported higher educational levels among the pregnant women, this influences their knowledge on malaria prevention. This might 
own to the fact that there are several infrastructure developments in the setting (schools Primary, secondary, and even university, electricity, road network, police station) which makes it a practically semi-urban setting. Even though the religious beliefs in the area are quite known; Christian, Islam, and Tradition, in this study majority were Christianity followed by Islam worshippers, a replica of their beliefs, perhaps is dominated by Christianity as a result of the missionary organization of the Seventh-day Adventist in the area and others peri-urban Christian missionary bodies and schools such as Theological school, Iperu-Ogere area and quite number of different churches around them as in line with Nwomha, Audu\& Dickson, (2010). Predominantly, pregnant women in this setting are Yoruba specifically, Remo, follow by Igbo, Hausa, and minority (Egun, Irobo).

The women's income level varied, although a majority of them had a source of income and corroborates the findings of (Goshu\&Yitayew, 2018; Sabin et al., 2018) reported that a significant number of the participants had a source of income. However, this may be as a result of their industrious abilities and development in the area that made it possible for them to earn.

\section{Patterns of Malaria Prevention among pregnant women}

The various measures of malaria prevention used in this present study were majorly the cleaning of surroundings, clearing bushes, windows and doors netting/screen, IPT, closing of windows and doors which are in line with measures commonly used for malaria prevention generally by pregnant women both at the rural and urban areas. This affirmed to Adeneye, Jegede and Adeniyi, (2016); Adebayo, Akinyemi and Cadmus, (2015); Khadivzadeh\&Ghabel, (2012); Okafor et al., (2019); FMOH, (2015); Sam-wobo et al., (2017); Idowu et al., (2014) and Efunshile et al., (2014) conducted within Nigeria context, identified measures like IPT-SP as well to some studies conducted outside Nigeria by Khadivzadeh \& Ghabel, 2012; Erhun et al., 2015; Nyeko, Tumewesigye, and Halage, (2016).

Furthermore, in this study, malaria preventive measures such as the use of insecticide-treated nets (ITN) were low among pregnant women. These findings correspond with the studies conducted in Ogun State by Adeneye et al., (2013) at rural areas of Ijebu-igbo, and Adeniran, et al., (2015) at Imeko-Afon and Odeda Local government areas, Ahmed, Akinboboye, Ilesanmi, \&Oguntuase, (2017) and also affirm to the NDHS, (2018) and MICS, (2017) reports that less than average number of pregnant women in the last one year slept under ITN. Thus, this might contribute to the reason why malaria cases are still very common among pregnant women and also indicating the highest toll of malaria cases and deaths in pregnancy in Nigeria. In this study, nearly average number of the pregnant women always and often cleaned the environment, clear bushes, and tidy up their surrounding as measures of malaria prevention which is similar to the findings of Adebayo, Akinyemi and Cadmus, (2015); Idowu et al., (2014), and Efunshile et al., (2014).

Other behavioural measures of malaria prevention in this study like netting or screening of windows and doors, also closing of these objects were slightly high among pregnant women which are in line with the findings of Adebayo, Akinyemi, \& Cadmus, (2015); Idowu et al, (2014); Sam-wobo et al., (2017) and Yaya et al., (2017) though contrary to Adeneye et al., (2015) in Ogun State, however this acts might be attributed to the impact of health facilities, educational status, and development in the area. About an average proportion of the pregnant women used IPT both always and often, which is equivalent to the findings of Mbuet al., (2015) and Pell et al, (2016) but contrary to the findings of Akaba et al., (2015) and reports in the 
national data (NMICS, 2017 \& NDHS, 2018). Thus, this could be linked to the presence of functioning public and private health facilities in the area. Although, the IPT-SP used were not under DOTs as about two-thirds of pregnant women never used as recommended which is similar to findings of Akaba et al., (2015) and Efunshile, et al., (2016) in Nigeria, and as well outside Nigeria by Mbu et al., (2015) and Pell et al., (2016). This may be due to the IPT-DOTs pattern not given attention at health facilities and by the health attendants at various facilities.

Equally, other measures like indoor residual spray (IRS), mosquito coil, and repellant, buying drugs from patent medicine store were never used by a high number of pregnant women. This contradicts the findings of Efunshile et al, (2011) Mashin- Bello, 2015 and Okafor et al., (2019) in Nigeria and Sabin et al., 2018 in India. The reason may bethe fact that pregnant women are aware of its consequence from ANC facilities in the area. Nevertheless, some pregnant women resorted to spiritual measures and herbs for malaria prevention which corroborates findings of Erhun et al. (2015); Efunshile et al, (2011) and (Deresea\& Ali, 2016). And it might be linked to their beliefs particularly, churches and probably influences of their tradition as also stated in Negard et al., (2015) and Erhun et al. (2015) works.

\section{Factors Associated with patterns of malaria Prevention among pregnant women}

Based on the present findings, majority of the pregnant women claimed information from attending ANC, knowledge of malaria prevention, previous experiences, recommendation, cost and quality of care, and belief were truly associated with the patterns of malaria prevention used except for belief in traditional care which was at average. However, some recent studies by Maegan et al., (2010); Ezebunwa and Nwakocha, (2014) conducted both in rural and urban areas conform to the present study results, though none of the factors is significantly associated with the patterns of prevention, thus contrary to the studies of Okafor, Oluwole, Onigbogi, \&Ezekude, (2019).

\section{Discussion of Hypotheses}

In this study, the relationship between socio-demographic characteristics and prevention of malaria in pregnancy was tested and the result observed that there were statistically significant relationship between the religion, ANC facility and patterns of prevention of malaria in pregnancy, thus contrary to Ezebunwa\&Nwakocha, (2014) in Ondo State. However, this result might be linked to their beliefs particularly, the presence of churches and probably levels of health facilities distributed in the area.

\section{SUMMARY, CONCLUSION, AND RECOMMENDATION}

\section{Summary}

Malaria in pregnancy may not manifest signs and symptoms (febrile) like in other age groups, this is dangerous among pregnant women, though it is preventable and treatable. However, it is predominant in high transmission areas and often interferes with maternal-fetal exchange thereby causing low birth weight, stillbirths, abortions, preterm, failure to thrive ininfants and in pregnant women; anemia, miscarriage, and other related complications (shock and death) (WHO \&Bekele, 2016). Invariably, several concerted efforts made towards prevention and control of malaria using different measures, in which its patterns of adoption varied. Therefore, 
this study identified patterns of prevention of malaria used by pregnant women in IlishanRemo, Ikenne Local Government Area, Ogun State. Reviewed literature was done on the conceptual, empirical, and theoretical for the patterns of prevention of malaria in pregnancy.

A cross-sectional survey design was used and a selected proportionate 271 consented pregnant women purposively recruited in four ANC health care facilities, Ilishan-Remo. A selfadministered questionnaire was used to collect data on socio-demographic, patterns of prevention, and factors associated with the prevention of malaria in pregnancy. The instrument was pre-tested among 27 pregnant women at ANC facility, PHC Ward-five Iperu-Remo. Administered instrument was valid and reliable after analysis for reliability with Cronbach's alpha coefficient score of $0.82,0.78$ and 0.73 as well face and content validity fulfilled. Data collected from pregnant women at ANC facilities on the ANC clinic days and retrieved for statistical analysis with SPSS version 23 for descriptive, bivariate, and tested hypotheses using chi-square at $\mathrm{P}$-value $\leq 0.005$.

Pregnant women age range was majorly (35.4\%) between ages 31-35years and mainly into trading, civil service, and apprentice. Predominantly Christian (80.8\%), pregnant women had different education, almost half $(49.1 \%)$ had tertiary education. About two-thirds $(64.6 \%)$ were Yoruba, and earned varied income on monthly basis. Slightly more than half (57.9\%) never slept in the net. Majority (83.8\%) never used herbs as prevention. Above half (52.4\%) never cleaned drainages. IPT-SP Fansidar was used respectively by $30.3 \%$ and $19.2 \%$ of pregnant women often and always, Majority (62.7\%) never used it under DOT. On pattern categorization of prevention, $54.2 \%$ used convention, $39.1 \%$ both convention and non-convention. There was a significant relationship between ANC facilities $\left(\chi^{2}=20.291\right)$, Beliefs $\left(\chi^{2}=16.540\right)$ and pattern of prevention at $\mathrm{p}<0.005$.

Conventional patterns of prevention used by half of the pregnant women and influenced by health facilities and non-convention were also common in this study. Hence, there is still a need to encourage pregnant women to follow standard of FMOH/WHO and conventional patterns of malaria prevention and management.

\section{Conclusion}

Pregnant women adopted different patterns of prevention for malaria by using various measures at different rates included; herbs, mosquitoes coil, mosquito repellants, spiritual homes water, oil, soap as well attending prayers, fansidar, procured medicine from patent stores, insecticides spray. Some pregnant women also engaged in behavioral activities such as sanitation, sleeping in the net, and wearing protective clothing. Though a higher proportion of the pregnant women adopted methods of cleaning, closing and screening/netting of windows and doors as well took IPT-sp while majority were not taking IPT-sp under direct observational therapy (DOT). Nevertheless, pregnant women's usage of patterns of prevention of malaria in pregnancy largely depends on their socio-demographic characteristics and associated factors, although the ANC facilities and beliefs only were found to be significantly related to the patterns of prevention of malaria in pregnancy. 


\section{Recommendation}

Based on the findings from this study, the researcher recommended the following:

1. There is a need for midwives and other health attendants to encourage pregnant women whenever they are approached or at ANC clinic to desist from using non- recommend patterns of prevention of malaria in pregnancy.

2. There is also a need for re-intensifying and continuous health talks and education on $\mathrm{WHO} / \mathrm{FMoH}$ recommendation patterns of malaria prevention in pregnancy; such as using Intermittent Preventive Therapy (IPT-Fansidar), insecticide-treated net(ITN), and prompt case management as the way to protect and manage malaria in pregnancy effectively. More so, it is evident from this study that there is still need for midwives to ensure direct observational therapy of IPT-Fansidar administration to pregnant women.

3. The government should ensure constant provision and supply of malaria preventive and management measures availability at all times in the health facilities to pregnant women and engage in an outreach program for mass distribution of malaria preventive and management measures to pregnant women.

\section{Suggestion for Further Studies}

The researcher suggested the following based on the findings from the study the need to cover more grounds:

1. The scope of the research can be increased by other researchers for more generalization of the findings.

2. Other researchers can explore how pregnant women used the selected patterns of prevention of malaria in pregnancy.

3. The research would also suggest a qualitative method of approach for this study and as well a comparative study to ascertain the true relationship between the settings and its associated and socio-economic factors that might be influencing patterns of prevention of malaria in pregnancy.

4. The research would also suggest that the limitation to the orthodox area would not reflect the situation of pattern as it might introduce bias, rather a total community-based study probably including all ANC facilities both orthodox and alternative care that pregnant women patronize in a given set of study.

\section{Limitation of the study}

1. Some of the participants were initially reluctant in participating in the study thinking much of their time will be taken.

2. The study is limited to the quantitative approach design.

3. The study scope is mainly within the public government ANC facilities and a faith-based tertiary health facility. 
4. The time frame delimits the study for being a robust and extensive study and as well the present Covid-19 pandemics which affected the regular routine essential healthcare services activities, thus reducing the pregnant women visiting the ANC scheduled.

\section{Nursing Implication of the study}

\section{Nursing practice}

Nurse/midwives within the community should intensify health education on the preventive measures and management of malaria among pregnant women. They should be encouraged to take WHO malaria preventive and management measures during pregnancy.

\section{Nursing Education}

All nurses in the community should continually undergo some educative training on prevention of malaria in pregnancy as this will help them in passing necessary information to the pregnant women during ante-natal clinics how to prevent and manage malaria pregnancy.

There should be in-service training for nurses on WHO recommended patterns of malaria prevention during pregnancy. This will help the nurses/midwives manage the pregnant women correctly to prevent any complications that may arise from contracting malaria.

\section{Nursing Administration}

Based on the findings of this study, useful polices and plans can be developed to sensitize pregnant women to make use of WHO patterns of malaria prevention during pregnancy and also the administration should ensure the availability of ITN and SP in our various ante-natal care facilities, which will contribute to the reduction of malaria in pregnancy. Policy makers should also organize continuous education programs for midwives to update their knowledge about current prevention of malaria in pregnancy.

\section{Nursing Research}

More research studies related to patterns of prevention of malaria in pregnancy should be considered.

\section{REFERENCES}

Adebayo, A.M., Akinyemi, O.O.,\& Cadmus, E.O.(2015). Knowledge of malaria prevention among pregnant women in rural southwest Nigeria.Peer Journal, 3, e792.

Adeneye, A.K., A.S. Jegede, M.A., Mafe, E.E.,\&Nwokocha, (2016)."A Pilot Study to Evaluate Malaria Control Strategies in Ogun State, Nigeria."World Health and Population 9(2): 83-94.Retrieved fromhttps://longwoods.com/content/19003.

Akaba, J., Otubu, E.T., Agida, O.,\&Onafowokan.O. (2015). Knowledge and utilization of malaria preventive measures among pregnant women at a tertiary hospital in Nigeria Federal Capital Territory.Niger Journal of Clinical Practise, 16:201-6.

Akanbi, O.M., Omonkhua, A.A., Cyril-Olutayo, C.A.,\&Fasimoye, R.Y., (2009). The antiplasmodial activity of Anogeissusleiocarpus and its effect on oxidative stress and 
lipid profile in mice infected with Plasmodium berghei. Parasitology Research.110 (1), 219-226.

Bekele, M., Tilahun, \&Mekuria, A. (2016).Prevalence of Anemia and Its Associated Factors among Pregnant Women Attending Antenatal Care in Health Institutions of Arba Minch Town, GamoGofa Zone, Ethiopia: A Cross-Sectional Study, " Anemia, vol., Article ID 1073192

Desai, M. Gutman, J., Taylor, S.M., Wiegand, R.E., Khairallah, C.,\&Kayentao, K. (2016).Impact of sulfadoxine-pyrimethamine resistance on effectiveness of intermittent preventive therapy for malaria in pregnancy at clearing infections and preventing low birth weight, 62(1), 323-33.

Efunshile, M. Amoo, A.O., Akintunde, G.B., Ojelekan, O.D., König, W., König, B., Korean, J. (2015)Use and effects of malaria control measures in pregnancy in Lagos, Nigeria.571. doi: 10.3347/kjp.2011.49.4.365.

Eijk, A.M., Hill, J., Noor, A.M., Snow, R.W., terKuile, F.O.(2015). Prevalence of malaria infection in pregnant women compared with children for tracking malaria transmission in sub-Saharan Africa: a systematic review and meta-analysis.Lancet Global Health.3:e617-28.

Erhun, W.O., Agbani, E.O., Adesanya, S.O. (2015). Malaria prevention, knowledge, attitude, and practice in A Southwestern Nigerian community. African Journal Biomed $l$ Research, 8: 25-29.

Federal Ministry of Health. (2015). National guidelines \& strategies for malaria Prevention \& control during pregnancy. (A publication of the Federal Ministry of Health, Nigeria). Nigeria Maternal Health - malaria in pregnancy.

Federal Ministry of Health. (2016). National Anti-malaria Treatment Policy.

National Population Commission, (2006).Nigeria Demographic and Health Survey preliminary Report. Downloaded on 7/04/2014 from www.dhsprogram.com/pubs/pdf/PR41/PR41.pdf

Noland, G.S., Graves, P.M., Sallau ,A., Eigege, A., Emukah, E., Patterson, A.E., Ajiji, J., Okorofor, I., Oji, O.U.,\& Umar, M.(2018). Malaria prevalence, anemia and baseline intervention coverage prior to mass net distributions in Abia and Plateau States, Nigeria.BMC Infectious Diseases.14:168. doi: 10.1186/1471-2334-14-168.

Nwaomah, S.M., Audu, M.A., \& Dickson, T.U. (2010). The Impact of Religion and culture on Environmental Sustainability: A Case Study of Ilishan-Remo in Ogun State. Paper presented at the meeting

Okafor, I.P., Ezekude, C., Oluwole, E.O.,\& Onigbogi, O. O. (2019). Malaria in pregnancy: A community-based study on the knowledge, perception, and prevention among Nigerian women. Journal of Family Medical Primary Care. (4):1359-1364.

Pell, C., Meñaca, A., Afrah, N.A., Manda-Taylor, L., Chatio, S., Were, F., Hodgson, A., Hamel, M.J., Kalilani., L., Tagbor, H., \& Pool, R. (2016).Prevention and management of malaria during pregnancy: findings from a comparative qualitative study in Ghana, Kenya, and Malawi.Malaria Journal.12: 427.

Rogerson, S.J., Hviid, L., Duffy, P.E., Leke, R.F., \&Taylor, D.W. (2015) Malaria in pregnancy: pathogenesis and immunity. Lancet Infectious Diseases, 7 (2),105-17

Roll Back Malaria. (2018). The global malaria action plan. The Roll Back Malaria Partnership. Retrieved from: https://www.rbm.who.int/gmap/gmap.pdf

Sarbin, L.L., Brooks, M.I., Singh, M.P. \& Tuchman, J.W., (2018). Knowledge, attitude and practices regarding malaria prevention and treatment among pregnant women in Eastern India, The American Journal of Tropical Medicine and Hygiene, 82(6). 
African Journal of Health, Nursing and Midwifery

ISSN: 2689-9418

Volume 4, Issue 2, 2021 (pp. 105-128)

www.abjournals.org

World Health Organization report.(2019).Retrieved from https://www.who.int/malaria/publications/world-malaria-report-2019/en

World Health Organization. (2016). Malaria Fact Sheet. Retrieved from: http://www.who.int/mediacentre/factsheets/fs094/en.

World Health Organization.(2018). World Malaria Report. 